\title{
Developmental Psychobiology
}

\section{Emotion Regulation Strategy Usage Explains Links Between Institutional Caregiving and Elevated Internalizing Symptoms}

\begin{tabular}{|c|c|}
\hline Journal: & Developmental Psychobiology \\
\hline Manuscript ID & DEV-20-135.R2 \\
\hline Wiley - Manuscript type: & Research Article \\
\hline $\begin{array}{r}\text { Date Submitted by the } \\
\text { Author: }\end{array}$ & 25-Nov-2020 \\
\hline Complete List of Authors: & $\begin{array}{l}\text { Waizman, Yael; University of California Los Angeles, Psychology } \\
\text { Mendez Leal, Adriana; University of California Los Angeles, Psychology } \\
\text { Guassi Moreira, Joao; University of California Los Angeles, Psychology } \\
\text { Saragosa-Harris, Natalie; University of California Los Angeles, } \\
\text { Psychology } \\
\text { Ninova, Emilia; University of California Los Angeles, Psychology } \\
\text { Silvers, Jennifer; University of California Los Angeles, Psychology }\end{array}$ \\
\hline Keywords: & $\begin{array}{l}\text { Internalizing Symptoms, Institutional Care, Early Adversity, Cognitive } \\
\text { Reappraisal, Expressive Suppression }\end{array}$ \\
\hline
\end{tabular}




\title{
Emotion Regulation Strategy Usage Explains Links Between Institutional Caregiving and
} Elevated Internalizing Symptoms

\author{
Yael H. Waizman*, Adriana S. Méndez Leal, João F. Guassi Moreira, Natalie M. Saragosa- \\ Harris, Emilia Ninova, \& Jennifer A. Silvers* \\ Department of Psychology, University of California, Los Angeles
}

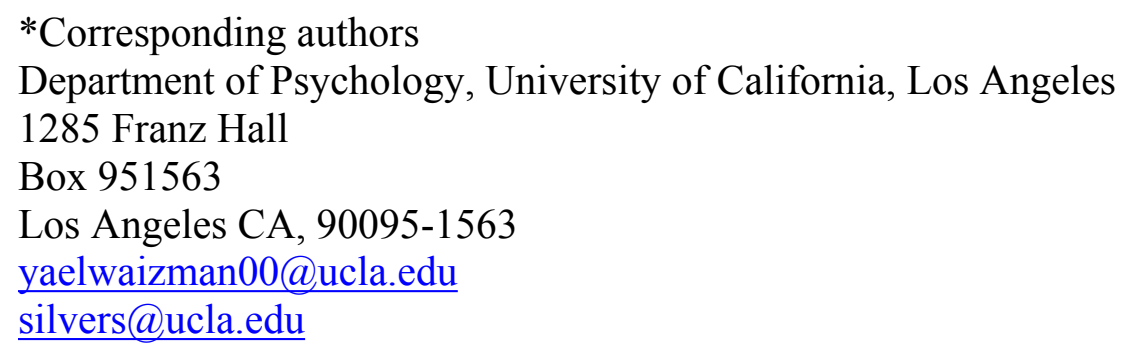




\section{Acknowledgments}

This work was supported by the UCLA academic senate and a National Science Foundation CAREER grant (1848004) to Jennifer Silvers. We thank Dr. Nim Tottenham for generously facilitating participant recruitment and to our participants for taking part in our study. We thank Dr. Bridget Callaghan for helpful comments on this manuscript. We thank Austin Blake, Zoey Dew, Milagro Escobar, Elizabeth Gaines, Tarran Walter, Ngoc Ngo, Emily Towner, Sakina Qadir, Agatha Handojo, Ciara Mandich, Claire Waller, and Alejandra Delgado for assisting in data collection. 
INSTITUTIONAL CARE AND EMOTION REGULATION

\section{Conflicts of Interest Statement}

The authors report no conflicts of interest. 
INSTITUTIONAL CARE AND EMOTION REGULATION

\section{Data Availability Statement}

The data that support the findings of this study are openly available on the Open Science

Framework at https://doi.org/10.17605/OSF.IO/HXRCW (Waizman et al., 2020). 


\begin{abstract}
Early adversity, including institutional orphanage care, is associated with the development of internalizing disorders. Previous research suggests that institutionalization can disrupt emotion regulation processes, which contribute to internalizing symptoms. However, no prior work has investigated how early orphanage care shapes emotion regulation strategy usage (e.g., cognitive reappraisal, expressive suppression) and whether said strategy usage contributes to internalizing symptoms. The present study probed emotion regulation strategy usage and internalizing symptoms in a sample of 36 previously institutionalized and 58 comparison youth. As hypothesized, previously institutionalized youth exhibited higher rates of internalizing symptoms than comparison youth, and more frequent use of suppression partially accounted for the relationship between early institutional care and elevated internalizing symptoms. Contrary to our initial hypotheses, reappraisal use did not buffer previously institutionalized or comparison youth against internalizing symptoms. Our findings highlight the potential utility of targeting emotion regulation strategy usage in adversity-exposed youth in future intervention work.
\end{abstract}

Keywords: Internalizing Symptoms, Institutional Care, Early Adversity, Cognitive Reappraisal, Expressive Suppression, Open Science 


\section{Introduction}

Exposure to early adversity, defined as negative experiences during childhood that deviate from the expected environment (e.g., absence of a primary caregiver) and require significant psychological, social, or neurological adaptation for a typical child (McLaughlin, 2016), significantly increases the risk of psychopathology, including mood and anxiety disorders (McLaughlin et al., 2010). This is true even for individuals for whom adversity exposure ceased in early childhood: for example, previously institutionalized (PI) youth who experienced orphanage care as infants and were adopted as young children remain at elevated risk for internalizing symptoms (Hawk \& McCall, 2010; Humphreys et al., 2015; Tottenham, 2012). Despite this fact, many PI youth do not develop psychopathology, underscoring how a combination of risk and resilience factors after exposure to early adversity impact mental health (Bimmel, Juffer, van IJzendoorn, \& Bakermans-Kranenburg, 2003; Méndez Leal \& Silvers, 2020). Emotion regulation ability is thought to be a potent source of resilience to internalizing disorders (and psychopathology in general) following early adversity (Jenness et al., 2020; Weissman et al., 2019), and variability in emotion regulation strategy use may, therefore, contribute to individual differences in internalizing symptoms present in PI youth. The current study sought to examine the differential use of emotion regulation strategies as factors that confer risk or resilience for internalizing symptomatology (anxiety, depression, somatic complaints, and withdrawal) among PI youth.

Emotion regulation, a collection of implicit (non-conscious) and explicit (controlled, effortful) strategies that modulate emotional processes, is essential for mental health (Aldao, Nolen-Hoeksema, \& Schweizer, 2010; Werner \& Gross, 2010). However, emotion regulation strategies vary in their effects on psychopathology. For example, expressive suppression is an 
emotion regulation strategy that involves suppressing the outward expression of emotion and is generally linked to decreased wellbeing (Cutuli, 2014; Haga et al., 2009). Cognitive reappraisal, by contrast, involves deliberately changing one's interpretation of emotional events and is thought to typically contribute to social and emotional health (Cutuli, 2014; Haga et al., 2009; Werner \& Gross, 2010; though see Ford \& Troy, 2019; Soto, Perez, Kim, Lee, \& Minnick, 2011 for caveats). However, little is known about how early experiences shape the use of emotion regulation strategies in general, and suppression and reappraisal in particular.

Various accounts suggest that exposure to early adversity can broadly disrupt emotion regulation processes, which in turn contributes to internalizing symptoms (Heleniak et al., 2016; Jenness et al., 2020; Kim \& Cicchetti, 2010; Pollak, 2008; Tottenham et al., 2010). However, little is known about how emotion regulation strategy usage contributes to internalizing problems in adversity-exposed youth in general, and PI youth specifically. An emerging body of work indicates that the use of reappraisal may promote resilience following early adversity (Johnson \& Tottenham, 2015; Rodman, Jenness, Weissman, Pine, \& McLaughlin, 2019). However, to our knowledge, no studies have examined how frequently PI youth use reappraisal and suppression, nor has any prior work examined the links between cognitive reappraisal or expressive suppression usage with internalizing symptoms in PI youth. The current study sought to test whether specific emotion regulation strategies differentially modify the effects of early institutional care on the development of internalizing symptoms. Specifically, we aimed to replicate and extend prior work linking the use of reappraisal to resilience in other adversityexposed populations (e.g., former foster youth) (Johnson \& Tottenham, 2015). We also aimed to test whether suppression would exacerbate links between experiencing orphanage care and internalizing symptoms. These questions were addressed using preregistered moderation and 
exploratory (not preregistered) path/mediation analyses. Our focus on PI youth was motivated by the fact that institutional orphanage care is a profound form of early adversity that offers a rare opportunity to isolate the effects of discrete and early, as opposed to prolonged exposure to adversity on emotion regulation processes and internalizing symptoms.

\section{Hypotheses}

The present study sought to test the following pre-registered (Open Science Framework; https://osf.io/ta9rh) a priori hypotheses:

H1: PI status will predict greater internalizing symptoms.

H2: Expressive suppression usage will be positively associated with internalizing symptoms across both PI and comparison groups.

H3: Cognitive reappraisal usage will be negatively associated with internalizing symptoms across both PI and comparison groups.

H4: Suppression usage will interact with PI status to predict internalizing symptoms (moderation analysis). Specifically, PI youth who frequently use expressive suppression will have higher internalizing symptoms than PI youth who do not.

H5: Reappraisal usage will interact with PI status to predict internalizing symptoms (moderation analysis). Specifically, PI youth who frequently use cognitive reappraisal will have fewer internalizing symptoms than PI youth who do not.

\section{Exploratory Analyses}

We additionally conducted exploratory (not preregistered) analyses to examine the following research questions: 
Q1: Does use of expressive suppression or cognitive reappraisal explain links between institutional caregiving and elevated internalizing symptoms (exploratory path/mediation analyses)?

Hypotheses, analysis plans, and results for additional exploratory questions (Q2 and Q3) are discussed in the Supplemental Material available online.

\section{Method}

\section{Participants and Design}

Participants included 36 PI (23 females and 13 males; $M_{\text {age }}=14.473$, age-range $=9-17$ ) and 58 comparison youth ( 32 females and 26 males; $M_{\text {age }}=13.243$, age-range $\left.=9-17\right)$. PI youth were internationally adopted from institutional orphanage care $\left(M_{\mathrm{age}}\right.$ of adoption $=14.838$ months, $S D=9.214$, age range at adoption $=0.130-35.500$ months $)$. All participants were fluent in English and resided in the United States at the time of the study. This study was approved by the Institutional Review Board at the University of California, Los Angeles where testing took place. Participants provided informed assent, and their parents provided informed consent prior to participation.

Participants completed the measures for this analysis as part of a larger longitudinal study examining the long-term effects of institutional care on socioemotional development.

Participants from the larger project were included in the current study if they were between 9 and 17 years old, if they completed the Emotion Regulation Questionnaire for Children and Adolescents (ERQ-CA), and if their parents completed the Youth and Child Behavior Checklist for Ages 6-18 (CBCL/6-18). The participants completed the ERQ-CA on their own, while their parents completed the CBCL/6-18 on their behalf. Aside from the CBCL/6-18 being among the most widely used parent-report instrument when measuring youth symptoms, the value of 
including multiple informants, in particular parents, has been shown to be useful when assessing youth's anxiety (Achenbach \& Rescorla, 2001; Barbosa, Tannock, \& Manassis, 2002; Manassis, Mendlowitz, \& Menna, 1997).

Power analyses were not performed to determine our recruitment size due to this being the first study to examine both suppression and reappraisal in PI youth, but our sample is larger than other work examining ERQ and internalizing symptoms in early adversity-exposed individuals (Johnson \& Tottenham, 2015). While we originally planned to conduct this analysis with 50 participants per group, we were unable to achieve this goal in our PI group due to (1) difficulties in recruiting PI participants that were under the age of 18 (in part due to changing international adoption laws), and (2) recruitment for the current wave of the study was cut short by the coronavirus outbreak. We did not calculate post-hoc power analyses given current statistical recommendations, but do report confidence intervals for our primary results which may be a superior means for interpreting the null and positive effects (Dziak, Dierker, \& Abar, 2020).

\section{Materials}

Emotion Regulation Questionnaire for Children and Adolescents (ERQ-CA). This 10item self-report measure was adapted from Gross \& John (2003) to assess individual differences in the use of cognitive reappraisal (6-items) and expressive suppression (4-items). Reappraisal involves cognitively redefining an emotion-eliciting situation to change its emotional impact (example: "I control my feelings about things by changing the way I think about them"). Suppression involves inhibiting the outward expression of emotion (example: "I control my feelings by not showing them"). Participants responded on a 5-point Likert-scale ranging from Strongly Disagree to Strongly Agree. A higher sum of scores on each scale indicates a greater 
usage of that emotion regulation strategy. This measure has been shown to have construct and convergent validity, sound internal consistency, and stability over a 12-month period (Gullone \& Taffe, 2012). Furthermore, both the reappraisal $(\alpha=.817)$ and the suppression $(\alpha=.763)$ subscales have demonstrated acceptable reliability in our presented sample.

Child Behavior Checklist for Ages 6-18 (CBCL/6-18). Parents completed the CBCL/618 to assess internalizing behaviors in their children. An Internalizing Problems Index raw score was obtained for each participant by taking the sum of their Anxious/Depressed, Withdrawn/Depressed, and Somatic Complaints total scale scores from the CBCL/6-18 (Achenbach \& Rescorla, 2001). These raw CBCL Internalizing total scores were converted to normalized CBCL Internalizing T-scores following the CBCL/6-18 scoring guidelines (Achenbach \& Rescorla, 2001). This instrument has been shown to be reliable and valid (Achenbach \& Rescorla, 2001). Moreover, the Anxious/Depressed ( $\alpha=.837)$, the Withdrawn/Depressed $(\alpha=.753)$, and the Somatic Complaints $(\alpha=.762)$ subscales all demonstrated acceptable reliability in our presented sample.

\section{Procedures}

Participants and their parents completed questionnaires on Qualtrics in separate, private rooms. Before completing their respective questionnaires, an experimenter instructed them to read each question carefully and complete the surveys to the best of their knowledge.

\section{Analysis Plan}

Unless otherwise stated, all analyses were performed using R Version 1.2.5042 (R Core Team, 2020). The data and code used in this analysis are available on the Open Science Framework (https://osf.io/hxrcw/). PI status (Comparison youth $=0$, PI youth $=1)$ and sex $($ Male $=0$, Female $=1$ ) were dummy coded. We controlled for sex and age in all regression, mediation, 
INSTITUTIONAL CARE AND EMOTION REGULATION

and moderation analyses described below given that our PI sample was slightly older than our comparison sample and similar prior work has controlled for sex (Rodman et al. 2019).

Descriptive statistics, demographics, and group differences are depicted in Table S1 in the Supplemental Material.

\section{Planned analyses}

H1: PI status will predict internalizing symptoms. PI status was entered as a predictor of internalizing symptoms (CBCL Internalizing T-scores, standardized according to age and sex) while controlling for sex and age in a multiple regression analysis using R's $\operatorname{lm}()$ function.

\section{H2 and H3: Suppression and reappraisal usage will be associated with internalizing} symptoms. In line with our pre-registered hypotheses, we report correlations between suppression (H2), reappraisal (H3) and internalizing symptoms in Table 1. Here, we describe the results of separate multiple regression analyses using R's $\operatorname{lm}()$ function with each emotion regulation strategy as predictors of internalizing symptoms (CBCL Internalizing T-scores), while controlling for sex, age, and PI status. Unexpectedly, we found that reappraisal was not associated with internalizing symptomatology, and thus it was not examined further in exploratory analyses.

\section{H4: Suppression usage will moderate (exacerbate) the effects of prior}

institutionalization on internalizing symptoms. To examine the interaction between group and suppression on internalizing psychopathology, we utilized the PROCESS macro (version 3.5) in SPSS (Hayes, 2017). We used PROCESS Model 1, with PI group as the focal predictor, meancentered suppression scores as the moderator, sex and mean-centered age as covariates, and internalizing symptoms (CBCL Internalizing T-scores) as the outcome variable. 


\section{H5: Reappraisal usage will moderate (attenuate) the effects of prior institutionalization}

on internalizing symptoms. To examine the interaction between group and reappraisal on internalizing psychopathology, we utilized the PROCESS macro (version 3.5) in SPSS (Hayes, 2017). We used PROCESS Model 1, with PI group as the focal predictor, mean-centered reappraisal scores as the moderator, sex and mean-centered age as covariates, and internalizing symptoms (CBCL Internalizing T-scores) as the outcome variable.

Exploratory analyses (not preregistered)

Q1: Does use of expressive suppression explain links between institutional caregiving and elevated internalizing symptoms (exploratory path/mediation analyses)? We used PROCESS Model 4 in SPSS, with PI group as the focal predictor, sex and mean-centered age across all participants as covariates, internalizing symptoms (CBCL Internalizing T-scores) as the outcome variable, and mean-centered suppression scores as the variable accounting for the relationship between the focal predictor and outcome variable. Significance was assessed using 10,000 percentile bootstrapping samples and $95 \%$ confidence intervals.

Given that our measures were collected at one-time point, and previous work suggesting that suppression is generally maladaptive and emotion regulation processes more broadly being a transdiagnostic mechanism to psychopathology (Heleniak et al., 2016; Weissman et al., 2019), we sought to investigate whether suppression usage (M) statistically accounts for the relationship between PI status (X) and internalizing symptoms (Y) without making assumptions of temporal causality. In line with recommendations regarding path/mediation analyses on concurrently collected data, we did not examine alternative models involving these variables (i.e., switching the M and Y variables) (Lemmer \& Gollwitzer, 2017; Thoemmes, 2015).

Reappraisal was not tested in Q1, as it was not related to internalizing symptoms in $\mathrm{H} 3$. 


\section{Results}

H1 Results: PI status will predict internalizing symptoms. In line with our hypothesis and with past research (Hawk \& McCall, 2010; Humphreys et al., 2015; Tottenham, 2012), PI status was associated with greater internalizing symptoms after controlling for sex and age, such that on average a given PI youth had 5.745 more units of internalizing symptoms than a comparison youth of the same sex and age $(B=5.745, \mathrm{t}=2.595, p=.011)$. Moreover, PI youth $(M=56.972, S D=10.864)$ exhibited significantly greater internalizing symptoms than comparison youth $(M=50.345, S D=9.624), \mathrm{t}(67.556)=3.002, p=.004)$ as shown in Table S1 in the Supplemental Material. Overall, $6.897 \%$ of comparison and $30.556 \%$ of PI youth had internalizing symptoms above the clinical cut-off with CBCL Internalizing T-scores greater than 64 for males and 63 for females.

\section{H2 and H3 Results: Suppression and reappraisal usage will be associated with}

internalizing symptoms. In line with our pre-registered hypotheses, we report correlations between suppression $(\mathrm{H} 2)$, reappraisal $(\mathrm{H} 3)$ and internalizing symptoms in Table 1. Here, we describe the main effects of suppression and reappraisal usage on internalizing symptoms after accounting for PI status, sex, and age in multiple regression analyses. As expected, suppression usage was associated with greater internalizing symptoms, such that 1-unit in suppression usage on average corresponded to 0.981 more units in internalizing symptoms $(B=0.981, t=2.833, p$ $=.006)$. Contrary to expectations, reappraisal usage was not associated with lower internalizing symptoms $(B=0.235, t=.835, p=.406)$. As described in the Supplemental Material, both comparison and PI participants reported lower levels of reappraisal than published norms from a similar age group, whereas comparison participants endorsed marginally lower use of 
suppression and PI participants reported comparable suppression levels to norms (Gullone \& Taffe, 2012).

\section{H4 Results: Suppression usage will moderate (exacerbate) the effects of prior}

institutionalization on internalizing symptoms. PI status predicted marginally higher internalizing symptoms at average levels of suppression usage $(B=4.193, t=1.914, p=.059)$, when accounting for mean-centered age and sex. Thus, a PI and comparison youth of the same sex and age who reported average suppression usage scores (10.26 in this sample) differed by an average of 4.193 units of CBCL Internalizing T-scores, with the PI youth displaying more internalizing symptoms. The interaction between PI status and suppression failed to predict internalizing psychopathology $(B=.781, t=1.109, p=.271)$, suggesting that use of suppression did not moderate the effect of PI status on internalizing symptoms.

H5 Results: Reappraisal usage will attenuate (moderate) the effects of prior institutionalization on internalizing symptoms. PI status positively predicted internalizing symptoms at average levels of reappraisal usage $(B=5.870, t=2.626, p=.010)$. Thus, a PI and comparison youth of the same sex who reported average reappraisal usage scores (19.85 in this sample) differed by an average of 5.870 units of CBCL Internalizing T-scores, with the PI youth displaying more internalizing symptoms. The interaction between PI status and reappraisal failed to predict internalizing symptoms $(B=.298, t=.514, p=.609)$, suggesting that the use of suppression did not moderate the effect of PI status on internalizing symptoms.

Q1 Results: Does use of expressive suppression explain links between institutional caregiving and elevated internalizing symptoms (exploratory path/mediation analyses)? A path analysis revealed that PI status indirectly influenced the development of internalizing symptoms through its effect on suppression while controlling for sex and mean-centered age (Figure 1). 
Bootstrap analyses revealed that the indirect effect was positive and significant ( $a b$; indirect effect $=1.299$ ), such that relative to comparison youth, PI youth on average had 1.299 more units of internalizing symptoms via their use of suppression $(10,000$ bootstrap samples; $95 \% \mathrm{CI}$ : [.0001 - 3.1137]). Overall, PI status predicted greater internalizing scores $(c$; total effect $=5.745$, $\mathrm{t}=2.595, p=.011)$. Additionally, participants in the PI group reported employing greater levels of suppression than the comparison group $(a$; coefficient $=1.325, \mathrm{t}=2.040, p=.044)$, and greater use of suppression predicted more internalizing problems, even after controlling for group status $(b$; coefficient $=.981, \mathrm{t}=2.833, p=.006)$. The indirect path between PI status and internalizing symptoms via expressive suppression accounted for $23 \%$ (percent $=[a b=$ $1.325 * 0.981] /[c=5.745])$ of the total effect of institutional rearing on subsequent internalizing symptomatology. After accounting for the indirect effect, PI status continued to exert a significant direct effect on internalizing symptoms $\left(c^{\prime} ;\right.$ direct effect $\left.=4.446, \mathrm{t}=2.038, p=.045\right)$, suggesting that expressive suppression does not fully account for this relationship. As noted in the Methods, parallel analyses were not performed on reappraisal scores given that neither PI status nor internalizing symptoms were associated with reappraisal usage.

\section{Discussion}

Given the extensive evidence that early adversity is associated with multiple forms of psychopathology, identifying factors that put an individual at a greater risk for poor mental health outcomes is crucial. This study examined how early adversity (in the form of institutional caregiving), impacts emotion regulation usage and whether such usage accounts for the relationship between early adversity and internalizing symptoms. We found that on average, PI youth exhibited greater internalizing symptoms than comparison youth in the present sample, but that there was a degree of variability among PI youth. Contrary to hypotheses, emotion 
regulation strategy (suppression or reappraisal) usage did not moderate the effect of PI status on internalizing symptoms and the use of reappraisal did not buffer PI or comparison individuals against internalizing symptoms. Instead, exploratory analyses revealed that the use of suppression partially explained the link between PI status and internalizing symptoms.

In the present study, PI youth utilized suppression more frequently than comparison youth, and suppression usage accounted for $23 \%$ of the relationship between PI status and internalizing symptoms. As noted in the Supplemental Material, PI youth reported did not report significantly greater use of expressive suppression than youth in published norms. Thus, while use of expressive suppression contributed to group differences in internalizing symptoms in the present sample, the present study does not provide conclusive evidence that PI youth use expressive suppression more than youth in the general population. On the CBCL/6-18, a 1-unit increase in internalizing T-scores is sufficient to place an individual in the borderline clinical range from the normal range, whereas, a 2-unit increase is enough to shift between the borderline to the clinical range. Thus, it is worth noting that the magnitude of change found between the total and indirect paths of 1.299 units is almost enough of a change needed to place an individual in the clinical range and is greater than the change needed to place an individual in the borderline clinical range. Future work will need to further interrogate the potential clinical significance of our findings. Although, prior work has linked the use of suppression to decreased positive affect and wellbeing and enhanced negative affect, depressed mood, and psychopathology (Cutuli 2014; Haga et al. 2009; Weissman et al. 2019). In accordance with this line of research, our findings suggest that suppression is a contributing risk factor to internalizing symptomatology following institutional rearing, and that expressive suppression usage may be more pronounced 
in PI youth. As such, this study highlights that future work ought to consider emotion regulation strategy usage as a target for mental health interventions in adversity-exposed youth.

While suppression partially accounted for the relationship between orphanage care and subsequent internalizing symptoms, it did not explain this link entirely. Thus, other potential mechanisms should be assessed in future work to identify additional factors that put an individual at greater risk for psychopathology following early adversity. For example, at the individual level, difficulties with cognitive control processes alongside reward, informational, and emotional processing biases may contribute to poor outcomes following early adversity (Duffy, McLaughlin, \& Green, 2018; Lambert, King, Monahan, \& McLaughlin, 2017; Machlin, Miller, Snyder, McLaughlin, \& Sheridan, 2019). Additionally, accumulating evidence indicates that familial factors, such as parental anxiety, parental emotion regulation abilities, parental control, and parent-child attachment, may also modify the etiology of anxiety disorders in children and adolescents (Bruggen, Stams, \& Bögels, 2008; Callaghan et al., 2019; Gee et al., 2014; McLaughlin, Behar, \& Borkovec, 2008; Tottenham, 2015). It is critical for future research to investigate these individual- and family-level factors alongside emotion regulation strategies to examine how they interact in predicting internalizing psychopathology in youth exposed to institutional caregiving, as well as other forms of early adversity.

Unexpectedly, we did not find a relationship between reappraisal usage and internalizing symptoms in either group. Thus, we did not replicate prior findings associating reappraisal use with improved mental health outcomes in adults (Gross \& John, 2003). The ability to reappraise effectively develops over the course of adolescence, and children and adolescents use reappraisal less frequently and less effectively than adults (Garnefski, Legerstee, Kraaij, Van Den Kommer, \& Teerds, 2002; Silvers et al., 2017). We did find that both of our groups endorsed significantly 
lower levels of reappraisal than published norms (described in Supplemental Material). It is therefore possible that our participants may not have engaged in enough successful effortful emotion regulation to produce meaningful effects on internalizing symptoms.

While this is a compelling first step in assessing whether emotion regulation tendencies account for greater internalizing symptomatology following institutional care, this study has several limitations. First, all measures in this study were questionnaires and may be subject to self-report biases. However, our use of multiple informants is valuable as we are not relying on self-report measures from the same individual (Barbosa et al., 2002; Manassis et al., 1997), but still observed correspondences between the CBCL/6-18 and ERQ-CA. Additionally, the fact that both measures have been validated in child and adolescent samples, and all subscales were found to be reliable in our sample, are strengths to our approach (Achenbach \& Rescorla, 2001; Gullone \& Taffe, 2012). However, we do note that youth internalizing symptoms observed in this study were based on parent-report only. As such, it will be important to replicate findings using multiple measures of internalizing symptoms in future analyses. We also plan to use behavioral measures of emotion regulation in future analyses. Second, the exploratory path/mediation analyses implicating expressive suppression in links between institutionalization and internalizing symptoms do not account for temporal ordering. In accordance with prior findings linking suppression with poor mental health outcomes and emotion regulation processes more broadly being a transdiagnostic mechanism to psychopathology (Heleniak et al., 2016; Weissman et al., 2019), we examined suppression as a mediator for the relationship between institutional care and internalizing symptoms. While this framework aligns with accepted guidelines for interpreting mediation analyses (Lemmer \& Gollwitzer, 2017; Thoemmes, 2015), future work should use longitudinal data to formally investigate the directionality of the 
relationship between suppression and internalizing symptoms. Another important future direction will involve exploring potential causal mechanisms for links between early caregiving adversity and use of expressive suppression. Third, institutional rearing is one particularly extreme form of early adversity, and it is unknown whether the present findings are likely to generalize to other, more common forms of adversity such as poverty, abuse, or neglect. While initial data from maltreated children suggests that they might (Heleniak et al., 2016; Weissman et al., 2019), more work is needed to examine links between emotion regulation strategy usage and internalizing symptoms in the context of various childhood adversities. Lastly, replication in a larger sample size would increase our confidence in the observed effects regarding suppression and the null effects related to reappraisal. A larger sample size would also enhance our ability to interrogate interactions between age and early adversity exposure on emotion regulation strategy use.

The current study examined factors that may confer risk and resilience for internalizing psychopathology following institutional caregiving. This study provides evidence for how adversity that is specific to early childhood, rather than across multiple developmental stages, impacts long-term psychological functioning. To our knowledge, this is the first study to address within-subject links between suppression, reappraisal, and internalizing symptoms in PI youth. Our findings regarding links between expressive suppression and internalizing symptoms suggest that targeting maladaptive emotion regulation strategies could be a fruitful avenue for helping youth exposed to caregiving adversity. 


\section{References}

Achenbach, T. M., \& Rescorla, L. (2001). Manual for the ASEBA school-age forms \& profiles: An integrated system of multi-informant assessment. Burlington, VT: ASEBA.

Aldao, A., Nolen-Hoeksema, S., \& Schweizer, S. (2010). Emotion-regulation strategies across psychopathology: A meta-analytic review. Clinical Psychology Review, 30, 217-237.

Barbosa, J., Tannock, R., \& Manassis, K. (2002). Measuring anxiety: Parent-child reporting differences in clinical samples. Depression and Anxiety, 15(2), 61-65.

Bimmel, N., Juffer, F., van IJzendoorn, M. H., \& Bakermans-Kranenburg, M. J. (2003). Problem behavior of internationally adopted adolescents: A review and meta-analysis. Harvard Review of Psychiatry, 11(2), 64-77.

Bruggen, C. O. V. D., Stams, G. J. J. M., \& Bögels, S. M. (2008). Research Review: The relation between child and parent anxiety and parental control: a meta-analytic review. Journal of Child Psychology and Psychiatry, 49(12), 1257-1269.

Callaghan, B. L., Gee, D. G., Gabard-Durnam, L., Telzer, E. H., Humphreys, K. L., Goff, B., ... Tottenham, N. (2019). Decreased Amygdala Reactivity to Parent Cues Protects Against Anxiety Following Early Adversity: An Examination Across 3 Years. Biological Psychiatry: Cognitive Neuroscience and Neuroimaging, 4(7), 664-671.

Cicchetti, D., \& Toth, S. L. (2005). Child Maltreatment. Annual Review of Clinical Psychology, $1,409-438$.

Cutuli, D. (2014). Cognitive reappraisal and expressive suppression strategies role in the emotion regulation: An overview on their modulatory effects and neural correlates. Frontiers in Systems Neuroscience, 8,175

Duffy, K. A., McLaughlin, K. A., \& Green, P. A. (2018). Early life adversity and health-risk 
INSTITUTIONAL CARE AND EMOTION REGULATION

behaviors: Proposed psychological and neural mechanisms. Annals of the New York Academy of Sciences, $1428(1), 151$.

Dziak, J. J., Dierker, L. C., \& Abar, B. (2020). The Interpretation of Statistical Power after the Data have been Gathered. Current Psychology (New Brunswick, N.J.), 39(3), 870-877.

Ford, B. Q., \& Troy, A. S. (2019). Reappraisal Reconsidered: A Closer Look at the Costs of an Acclaimed Emotion-Regulation Strategy. Current Directions in Psychological Science, 28(2), 195-203.

Garnefski, N., Legerstee, J., Kraaij, V., Van Den Kommer, T., \& Teerds, J. (2002). Cognitive coping strategies and symptoms of depression and anxiety: A comparison between adolescents and adults. Journal of Adolescence, 25(6), 603-611.

Gee, D. G., Gabard-Durnam, L., Telzer, E. H., Humphreys, K. L., Goff, B., Shapiro, M., ... Tottenham, N. (2014). Maternal buffering of human amygdala-prefrontal circuitry during childhood but not during adolescence. Psychological Science, 25(11), 2067-2078.

Green, J. G., McLaughlin, K. A., Berglund, P. A., Gruber, M. J., Sampson, N. A., Zaslavsky, A. M., \& Kessler, R. C. (2010). Childhood adversities and adult psychiatric disorders in the national comorbidity survey replication I: Associations with first onset of DSM-IV disorders. Archives of General Psychiatry, 67, 113-123.

Gross, J. J., \& John, O. P. (2003). Individual differences in two emotion regulation processes: Implications for affect, relationships, and well-being.

Gullone, E., \& Taffe, J. (2012). The Emotion Regulation Questionnaire for Children and Adolescents (ERQ-CA): A psychometric evaluation. Psychological Assessment, 24, 409417.

Haga, S. M., Kraft, P., \& Corby, E.-K. (2009). Emotion Regulation: Antecedents and Well-Being 
Outcomes of Cognitive Reappraisal and Expressive Suppression in Cross-Cultural Samples. Journal of Happiness Studies, 10, 271-291.

Hawk, B., \& McCall, R. B. (2010). CBCL behavior problems of post-institutionalized international adoptees. Clinical Child and Family Psychology Review, 13, 199-211.

Hayes, A. F. (2017). Introduction to Mediation, Moderation, and Conditional Process Analysis, Second Edition: A Regression-Based Approach. New York, UNITED STATES: Guilford Publications.

Heleniak, C., Jenness, J. L., Stoep, A. V., McCauley, E., \& McLaughlin, K. A. (2016).

Childhood Maltreatment Exposure and Disruptions in Emotion Regulation: A Transdiagnostic Pathway to Adolescent Internalizing and Externalizing Psychopathology. Cognitive Therapy and Research, 40, 394-415.

Humphreys, K. L., Gleason, M. M., Drury, S. S., Miron, D., Nelson, C. A., Fox, N. A., \& Zeanah, C. H. (2015). Effects of institutional rearing and foster care on psychopathology at age 12 years in Romania: Follow-up of an open, randomised controlled trial. The Lancet Psychiatry, 2, 625-634.

Jenness, J. L., Peverill, M., Miller, A. B., Heleniak, C., Robertson, M. M., Sambrook, K. A., ... McLaughlin, K. A. (2020). Alterations in neural circuits underlying emotion regulation following child maltreatment: A mechanism underlying trauma-related psychopathology. Psychological Medicine, 1-10.

Johnson, A. J., \& Tottenham, N. (2015). Regulatory Skill as a Resilience Factor for Adults With a History of Foster Care: A Pilot Study. Developmental Psychobiology, 57, 1-16.

Keyes, K. M., Eaton, N. R., Krueger, R. F., McLaughlin, K. A., Wall, M. M., Grant, B. F., \& Hasin, D. S. (2012). Childhood maltreatment and the structure of common psychiatric 
disorders. The British Journal of Psychiatry, 200, 107-115.

Kim, J., \& Cicchetti, D. (2010). Longitudinal pathways linking child maltreatment, emotion regulation, peer relations, and psychopathology. Journal of Child Psychology and Psychiatry, and Allied Disciplines, 51, 706-716.

Lambert, H. K., King, K. M., Monahan, K. C., \& McLaughlin, K. A. (2017). Differential associations of threat and deprivation with emotion regulation and cognitive control in adolescence. Development and Psychopathology, 29(3), 929.

Lemmer, G., \& Gollwitzer, M. (2017). The “true” indirect effect won't (always) stand up: When and why reverse mediation testing fails. Journal of Experimental Social Psychology, 69, $144-149$.

Machlin, L., Miller, A. B., Snyder, J., McLaughlin, K. A., \& Sheridan, M. A. (2019). Differential Associations of Deprivation and Threat With Cognitive Control and Fear Conditioning in Early Childhood. Frontiers in behavioral neuroscience, 13, 80.

Manassis, K., Mendlowitz, S., \& Menna, R. (1997). Child and parent reports of childhood anxiety: Differences in coping styles. Depression and Anxiety, 6(2), 62-69.

Méndez Leal, A.S., \& Silvers, J.A. (2020). Neurobiological Markers of Resilience to Early Life Adversity During Adolescence. Biological Psychiatry: Cognitive Neuroscience and Neuroimaging.

McLaughlin, K. A. (2016). Future Directions in Childhood Adversity and Youth Psychopathology. Journal of Clinical Child \& Adolescent Psychology, 45, 361-382.

McLaughlin, K. A., Behar, E., \& Borkovec, T. D. (2008). Family history of psychological problems in generalized anxiety disorder. Journal of Clinical Psychology, 64, 905-918.

McLaughlin, K. A., Green, J. G., Gruber, M. J., Sampson, N. A., Zaslavsky, A. M., \& Kessler, 
R. C. (2010). Childhood Adversities and Adult Psychiatric Disorders in the National Comorbidity Survey Replication II: Associations With Persistence of DSM-IV Disorders. Archives of General Psychiatry, 67, 124-132.

McLaughlin, K. A., \& Lambert, H. K. (2017). Child trauma exposure and psychopathology: Mechanisms of risk and resilience. Current Opinion in Psychology, 14, 29-34.

Nusslock, R., \& Miller, G. E. (2016). Early-Life Adversity and Physical and Emotional Health Across the Lifespan: A Neuroimmune Network Hypothesis. Biological Psychiatry, 80, $23-32$.

Pollak, S. D. (2008). Mechanisms Linking Early Experience and the Emergence of Emotions: Illustrations From the Study of Maltreated Children. Current Directions in Psychological Science, 17, 370-375.

R Core Team (2020). R: A language and environment for statistical computing. R Foundation for Statistical Computing, Vienna, Austria. URL https://www.R-project.org/.

Rodman, A. M., Jenness, J. L., Weissman, D. G., Pine, D. S., \& McLaughlin, K. A. (2019). Neurobiological Markers of Resilience to Depression Following Childhood Maltreatment: The Role of Neural Circuits Supporting the Cognitive Control of Emotion. Biological Psychiatry, 86, 464-473.

Silvers, J. A., Insel, C., Powers, A., Franz, P., Helion, C., Martin, R. E., ... Ochsner, K. N. (2017). V1PFC-vmPFC-Amygdala Interactions Underlie Age-Related Differences in Cognitive Regulation of Emotion. Cerebral Cortex (New York, NY), 27, 3502-3514.

Soto, J. A., Perez, C. R., Kim, Y.-H., Lee, E. A., \& Minnick, M. R. (2011). Is expressive suppression always associated with poorer psychological functioning? A cross-cultural comparison between European Americans and Hong Kong Chinese. Emotion, 11, 1450- 

1455.

Thoemmes, F. (2015). Reversing Arrows in Mediation Models Does Not Distinguish Plausible Models. Basic and Applied Social Psychology, 37, 226-234.

Tottenham, N. (2012). Risk and Developmental Heterogeneity in Previously Institutionalized Children. Journal of Adolescent Health, 51, S29-S33.

Tottenham, N. (2015). Social scaffolding of human amygdala-mPFCcircuit development. Social Neuroscience, 10, 489-499.

Tottenham, N., Hare, T. A., Quinn, B. T., McCarry, T. W., Nurse, M., Gilhooly, T., ... Casey, B. J. (2010). Prolonged institutional rearing is associated with atypically large amygdala volume and difficulties in emotion regulation. Developmental Science, 13, 46-61.

Waizman, Y. H., Méndez Leal, A. S., Guassi Moreira, J. F., Saragosa-Harris, N. M., Ninova, E., \& Silvers, J. A. (2020). Emotion Regulation Strategy Usage Explains Links Between Institutional Caregiving and Elevated Internalizing Symptoms. https://doi.org/10.17605/OSF.IO/HXRCW

Weissman, D. G., Bitran, D., Miller, A. B., Schaefer, J. D., Sheridan, M. A., \& McLaughlin, K. A. (2019). Difficulties with emotion regulation as a transdiagnostic mechanism linking child maltreatment with the emergence of psychopathology. Development and Psychopathology, 31, 899-915.

Werner, K., \& Gross, J. J. (2010). Emotion regulation and psychopathology: A conceptual framework. 


\section{Figure Legends}

Figure 1. Path Analyses. PI = previously institutionalized; The relationship between institutional caregiving and internalizing symptoms is partially explained by expressive suppression usage (while controlling for sex); Unstandardized coefficients are presented.

$* p<.05 . * * p<.01$ 
Table 1.

Correlations with confidence intervals for demographic and questionnaire data

\begin{tabular}{|c|c|c|c|c|c|}
\hline & Variable & 1 & 2 & 3 & 4 \\
\hline \multirow{9}{*}{ PI Youth } & 1. Age (years) & & & & \\
\hline & 2. Suppression & $\begin{array}{c}-.06 \\
{[-.38, .28]}\end{array}$ & & & \\
\hline & 3. Reappraisal & .03 & .10 & & \\
\hline & & {$[-.30, .36]$} & {$[-.24, .41]$} & & \\
\hline & 4. Internalizing & $.36^{*}$ & $.41^{*}$ & .17 & \\
\hline & Symptoms & {$[.04, .62]$} & {$[.09, .65]$} & {$[-.17, .47]$} & \\
\hline & 5. Institutionalization & .11 & .13 & -.06 & .15 \\
\hline & Duration (months) & {$[-.22, .43]$} & {$[-.21, .44]$} & {$[-.39, .27]$} & {$[-.18, .46]$} \\
\hline & Variable & 1 & 2 & 3 & 4 \\
\hline \multirow{7}{*}{$\begin{array}{l}\text { Comparison } \\
\text { Youth }\end{array}$} & 1. Age (years) & & & & \\
\hline & 2. Suppression & .02 & & & \\
\hline & 3. Reappraisal & $-.33 *$ & -.01 & & \\
\hline & & {$[-.54,-.07]$} & {$[-.27, .25]$} & & \\
\hline & 4. Internalizing & .02 & .21 & -.03 & \\
\hline & Symptoms & {$[-.24, .28]$} & {$[-.05, .45]$} & {$[-.28, .23]$} & \\
\hline & Variable & 1 & 2 & 3 & 4 \\
\hline \multirow{6}{*}{$\begin{array}{l}\text { Entire } \\
\text { Sample }\end{array}$} & 1. Age (years) & & & & \\
\hline & 2. Suppression & .05 & & & \\
\hline & 3. Reappraisal & $-.20 *$ & .02 & & \\
\hline & & {$[-.39,-.00]$} & {$[-.19, .22]$} & & \\
\hline & 4. Internalizing & $.23^{*}$ & $.34 * *$ & .03 & \\
\hline & Symptoms & {$[.02, .41]$} & {$[.15, .51]$} & {$[-.17, .23]$} & \\
\hline
\end{tabular}

Note. PI = previously institutionalized; Values in square brackets indicate the $95 \%$ confidence interval for each correlation; The confidence interval is a plausible range of population correlations that could have resulted in the sample correlation.

$* p<.05 .{ }^{* *} p<.01$. 


\section{INSTITUTIONAL CARE AND EMOTION REGULATION \\ Supplemental Material \\ Emotion Regulation Strategy Usage Explains Links Between Institutional Caregiving and \\ Elevated Internalizing Symptoms}

\section{Exploratory Analyses}

As noted in the main text, we conducted additional exploratory analyses to examine the following research questions:

Q1: Q1 is presented in the main text.

Q2: Is age associated with the usage of an emotion regulation strategy? If so, does this relationship differ for PI versus comparison youth?

Q3: Is the duration of institutional care associated with the usage of an emotion regulation strategy or internalizing symptoms?

Q4: Is the average reported use of expressive suppression and cognitive reappraisal in our PI and comparison groups similar to previous published norms of similar age groups?

\section{Analysis Plan \\ Exploratory analyses \\ Q2: Pearson correlation coefficients were computed using R's cor.test() function to assess links between suppression and age. The correlations are included in Table 1 in the main text.}

Q3: Pearson correlations were computed using R's cor.test() function were used to explore the links between institutionalization duration for PI youth, suppression, and internalizing symptoms. The correlations are included in Table 1 in the main text.

Cognitive reappraisal was not assessed in Q2 and Q3 due to this emotion regulation strategy not being associated with internalizing symptoms in $\mathrm{H} 3$ (depicted in the main text). 
Q4: One-sample t tests were computed using R's t.test() function to investigate whether each of our groups reported using similar levels of suppression and reappraisal to published norms of similar age groups.

Results

Q2 Results: Is age associated with suppression usage and does this relationship differ for PI versus comparison youth? Suppression usage was not correlated with age within or across groups (see Table 1).

\section{Q3 Results: Is the duration of institutional care associated with the usage of} suppression or internalizing symptoms? Within the PI group, duration of institutionalization was not correlated with suppression, nor with internalizing symptoms (see Table 1).

Q4 Results: Is the average reported use of expressive suppression and cognitive reappraisal in our PI and comparison groups similar to previous published norms of similar age groups? Participants were compared against published norms for similar-aged participants $\left(\mathrm{M}_{\text {Suppression }}=21.530, S D=3.860 ; \mathrm{M}_{\text {Reappraisal }}=10.490, S D=2.910 ;\right.$ Gullone $\&$ Taffe, 2012 $)$. Both comparison participants $(M=20.069, S D=3.699), \mathrm{t}(57)=-3.008, p=.004$, and PI participants $(M=19.500, S D=3.917), \mathrm{t}(35)=-3.110, p=.004$, reported significantly lower levels of reappraisal than published norms. Comparison participants endorsed marginally lower use of suppression $(M=9.759, S D=2.892), \mathrm{t}(57)=-1.926, p=.059)$, and PI participants reported comparable suppression levels to published norms $(M=11.056, S D=2.976), \mathrm{t}(35)=1.140, p=$ $.262)$. 


\section{Supplemental Tables}

Table S1.

Group means and standard deviations from demographic and questionnaire data

\begin{tabular}{|c|c|c|c|c|c|c|}
\hline & \multicolumn{3}{|c|}{$\mathrm{PI}(N=36)$} & \multicolumn{3}{|c|}{ Comparison $(N=58)$} \\
\hline & $\%$ & Mean $(S D)$ & Range & $\%$ & Mean $(S D)$ & Range \\
\hline Age (years) & & $14.47(1.92)$ & $9.9-17.7$ & & $13.24(2.13)^{* *}$ & $9.11-17.8$ \\
\hline Sex & $\begin{array}{l}63.89 \mathrm{~F} \\
(N=23)\end{array}$ & & & $\begin{array}{l}55.17 \mathrm{~F} \\
(N=32)\end{array}$ & & \\
\hline Suppression & & $11.06(2.98)$ & $5-18$ & & $9.76(2.89)^{*}$ & $4-16$ \\
\hline Reappraisal & & $19.50(3.92)$ & $7-26$ & & $20.07(3.70)$ & $12-28$ \\
\hline CBCL T-scores & & $56.97(10.86)$ & $33-76$ & & $50.34(9.62)^{* *}$ & $33-71$ \\
\hline $\begin{array}{l}\text { Institutionalization } \\
\text { duration (months) }\end{array}$ & & $12.63(7.07)$ & $.13-28$ & & 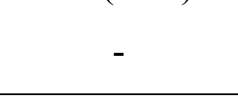 & \\
\hline Race/Ethnicity & $\%$ & & & $\%$ & & \\
\hline $\begin{array}{l}\text { African American/ } \\
\text { Black }\end{array}$ & $\begin{array}{c}0 \\
(N=0)\end{array}$ & & & $\begin{array}{c}6.90 \\
(N=4)\end{array}$ & & \\
\hline $\begin{array}{l}\text { Asian- } \\
\text { American/Asian }\end{array}$ & $\begin{array}{c}47.22 \\
(N=17)\end{array}$ & & & $\begin{array}{c}17.24 \\
(N=10)\end{array}$ & & \\
\hline $\begin{array}{l}\text { European- } \\
\text { American/Caucasian }\end{array}$ & $\begin{array}{c}33.33 \\
(N=12)\end{array}$ & & & $\begin{array}{c}44.83 \\
(N=26)\end{array}$ & & \\
\hline Hispanic/Latino & $\begin{array}{c}5.56 \\
(N=2)\end{array}$ & & & $\begin{array}{c}6.90 \\
(N=4)\end{array}$ & & \\
\hline Other & $\begin{array}{l}13.89 \\
(N=5)\end{array}$ & & & $\begin{array}{c}1.72 \\
(N=1)\end{array}$ & & \\
\hline Mixed & $\begin{array}{c}0 \\
(N=0)\end{array}$ & & & $\begin{array}{c}17.24 \\
(N=10)\end{array}$ & & \\
\hline $\begin{array}{l}\text { Unknown/ } \\
\text { Not Specified }\end{array}$ & $\begin{array}{c}0 \\
(N=0)\end{array}$ & & & $\begin{array}{c}5.17 \\
(N=3)\end{array}$ & & \\
\hline Parental Education & $\%$ & & & $\%$ & & \\
\hline High school degree & $\begin{array}{c}0 \\
(N=0)\end{array}$ & & & $\begin{array}{c}1.72 \\
(N=1)\end{array}$ & & \\
\hline Some College & $\begin{array}{c}5.56 \\
(N=2)\end{array}$ & & & $\begin{array}{c}6.90 \\
(N=4)\end{array}$ & & \\
\hline $\begin{array}{l}\text { Community college/ } \\
\text { two-year degree }\end{array}$ & $\begin{array}{c}0 \\
(N=0)\end{array}$ & & & $\begin{array}{l}8.62 \\
(N=5)\end{array}$ & & \\
\hline $\begin{array}{l}\text { Four-year college } \\
\text { degree }\end{array}$ & $\begin{array}{l}22.22 \\
(N=8)\end{array}$ & & & $\begin{array}{l}15.52 \\
(N=9)\end{array}$ & & \\
\hline $\begin{array}{l}\text { Some graduate } \\
\text { school }\end{array}$ & $\begin{array}{c}16.67 \\
(N=6)\end{array}$ & & & $\begin{array}{c}8.62 \\
(N=5)\end{array}$ & & \\
\hline Master's degree & $\begin{array}{l}13.89 \\
(N=5)\end{array}$ & & & $\begin{array}{c}29.31 \\
(N=17)\end{array}$ & & \\
\hline Doctoral degree & $\begin{array}{c}16.67 \\
(N=6)\end{array}$ & & & $\begin{array}{c}17.24 \\
(N=10)\end{array}$ & & \\
\hline Professional degree & $\begin{array}{c}22.22 \\
(N=8)\end{array}$ & & & $\begin{array}{c}3.45 \\
(N=2)\end{array}$ & & \\
\hline $\begin{array}{l}\text { No parental education } \\
\text { listed }\end{array}$ & $\begin{array}{c}2.78 \\
(N=1)\end{array}$ & & & $\begin{array}{c}8.62 \\
(N=5)\end{array}$ & & \\
\hline
\end{tabular}


Note. $\mathrm{PI}=$ previously institutionalized; $\mathrm{F}=$ female; $M=$ mean; $S D=$ standard deviation; $\mathrm{CBCL}$

T-scores $=$ Child Behavior Checklist for Ages 6-18 Internalizing T-scores; Participants were free to report more than one race or ethnicity (Mixed) or to not report (Unknown/Not Specified);

Parental education was obtained from the parent who provided consent for the study ( 80 female, 11 male, 3 not reported or not applicable); No parental education listed, parents who did not report their education level.

$* p<.05 .{ }^{* *} p<.01$ associated with independent samples t-tests. 


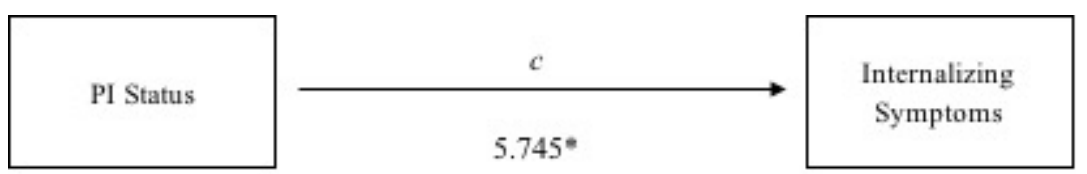

Figure 1. Path Analyses. PI = previously institutionalized; The relationship between institutional caregiving and internalizing symptoms is partially explained by expressive suppression usage (while controlling for sex); Unstandardized coefficients are presented. $* p<.05 . * * p<.01$.

$144 \times 100 \mathrm{~mm}(72 \times 72 \mathrm{DPI})$ 
Table 1.

Correlations with confidence intervals for demographic and questionnaire data

\begin{tabular}{|c|c|c|c|c|c|}
\hline & Variable & 1 & 2 & 3 & 4 \\
\hline \multirow{10}{*}{ PI Youth } & 1. Age (years) & & & & \\
\hline & 2. Suppression & -.06 & & & \\
\hline & & {$[-.38, .28]$} & & & \\
\hline & 3. Reappraisal & .03 & .10 & & \\
\hline & & {$[-.30, .36]$} & {$[-.24, .41]$} & & \\
\hline & 4. Internalizing & $.36^{*}$ & $.41 *$ & .17 & \\
\hline & Symptoms & {$[.04, .62]$} & {$[.09, .65]$} & {$[-.17, .47]$} & \\
\hline & 5. Institutionalization & .11 & .13 & -.06 & .15 \\
\hline & Duration (months) & {$[-.22, .43]$} & {$[-.21, .44]$} & {$[-.39, .27]$} & {$[-.18, .46]$} \\
\hline & Variable & 1 & 2 & 3 & 4 \\
\hline \multirow{7}{*}{$\begin{array}{l}\text { Comparison } \\
\text { Youth }\end{array}$} & 1. Age (years) & & & & \\
\hline & 2. Suppression & .02 & & & \\
\hline & 3. Reappraisal & $-.33 *$ & -.01 & & \\
\hline & & {$[-.54,-.07]$} & {$[-.27, .25]$} & & \\
\hline & 4. Internalizing & .02 & .21 & -.03 & \\
\hline & Symptoms & {$[-.24, .28]$} & {$[-.05, .45]$} & {$[-.28, .23]$} & \\
\hline & Variable & 1 & 2 & 3 & 4 \\
\hline \multirow{7}{*}{$\begin{array}{l}\text { Entire } \\
\text { Sample }\end{array}$} & 1. Age (years) & $P=$ & & & \\
\hline & 2. Suppression & .05 & & & \\
\hline & & {$[-.15, .25]$} & & & \\
\hline & 3. Reappraisal & $-.20 *$ & .02 & & \\
\hline & & {$[-.39,-.00]$} & {$[-.19, .22]$} & & \\
\hline & 4. Internalizing & $.23 *$ & $.34 * *$ & .03 & \\
\hline & Symptoms & {$[.02, .41]$} & {$[.15, .51]$} & {$[-.17, .23]$} & \\
\hline
\end{tabular}

Note. $\mathrm{PI}=$ previously institutionalized; Values in square brackets indicate the $95 \%$ confidence interval for each correlation; The confidence interval is a plausible range of population correlations that could have resulted in the sample correlation.

$* p<.05 . * * p<.01$. 


\section{INSTITUTIONAL CARE AND EMOTION REGULATION \\ Supplemental Material \\ Emotion Regulation Strategy Usage Explains Links Between Institutional Caregiving and \\ Elevated Internalizing Symptoms}

\section{Exploratory Analyses}

As noted in the main text, we conducted additional exploratory analyses to examine the following research questions:

Q1: Q1 is presented in the main text.

Q2: Is age associated with the usage of an emotion regulation strategy? If so, does this relationship differ for PI versus comparison youth?

Q3: Is the duration of institutional care associated with the usage of an emotion regulation strategy or internalizing symptoms?

Q4: Is the average reported use of expressive suppression and cognitive reappraisal in our PI and comparison groups similar to previous published norms of similar age groups?

\section{Analysis Plan \\ Exploratory analyses \\ Q2: Pearson correlation coefficients were computed using R's cor.test() function to assess links between suppression and age. The correlations are included in Table 1 in the main text.}

Q3: Pearson correlations were computed using R's cor.test () function were used to explore the links between institutionalization duration for PI youth, suppression, and internalizing symptoms. The correlations are included in Table 1 in the main text.

Cognitive reappraisal was not assessed in Q2 and Q3 due to this emotion regulation strategy not being associated with internalizing symptoms in $\mathrm{H} 3$ (depicted in the main text). 
INSTITUTIONAL CARE AND EMOTION REGULATION

Q4: One-sample t tests were computed using R's t.test() function to investigate whether each of our groups reported using similar levels of suppression and reappraisal to published norms of similar age groups.

Results

Q2 Results: Is age associated with suppression usage and does this relationship differ for PI versus comparison youth? Suppression usage was not correlated with age within or across groups (see Table 1).

Q3 Results: Is the duration of institutional care associated with the usage of suppression or internalizing symptoms? Within the PI group, duration of institutionalization was not correlated with suppression, nor with internalizing symptoms (see Table 1).

Q4 Results: Is the average reported use of expressive suppression and cognitive reappraisal in our PI and comparison groups similar to previous published norms of similar age groups? Participants were compared against published norms for similar-aged participants $\left(\mathrm{M}_{\text {Suppression }}=21.530, S D=3.860 ; \mathrm{M}_{\text {Reappraisal }}=10.490, S D=2.910 ;\right.$ Gullone $\&$ Taffe, 2012 $)$. Both comparison participants $(M=20.069, S D=3.699), \mathrm{t}(57)=-3.008, p=.004$, and PI participants $(M=19.500, S D=3.917), \mathrm{t}(35)=-3.110, p=.004$, reported significantly lower levels of reappraisal than published norms. Comparison participants endorsed marginally lower use of suppression $(M=9.759, S D=2.892), \mathrm{t}(57)=-1.926, p=.059)$, and PI participants reported comparable suppression levels to published norms $(M=11.056, S D=2.976), \mathrm{t}(35)=1.140, p=$ $.262)$. 
INSTITUTIONAL CARE AND EMOTION REGULATION

\section{Supplemental Tables}

Table S1.

Group means and standard deviations from demographic and questionnaire data

\begin{tabular}{|c|c|c|c|c|c|c|}
\hline & \multicolumn{3}{|c|}{$\mathrm{PI}(N=36)$} & \multicolumn{3}{|c|}{ Comparison $(N=58)$} \\
\hline & $\%$ & Mean $(S D)$ & Range & $\%$ & Mean $(S D)$ & Range \\
\hline Age (years) & & $14.47(1.92)$ & $9.9-17.7$ & & $13.24(2.13)^{* *}$ & $9.11-17.8$ \\
\hline Sex & $\begin{array}{l}63.89 \mathrm{~F} \\
(N=23)\end{array}$ & & & $\begin{array}{l}55.17 \mathrm{~F} \\
(N=32)\end{array}$ & & \\
\hline Suppression & & $11.06(2.98)$ & $5-18$ & & $9.76(2.89)^{*}$ & $4-16$ \\
\hline Reappraisal & & $19.50(3.92)$ & $7-26$ & & $20.07(3.70)$ & $12-28$ \\
\hline CBCL T-scores & & $56.97(10.86)$ & $33-76$ & & $50.34(9.62)^{* *}$ & $33-71$ \\
\hline $\begin{array}{l}\text { Institutionalization } \\
\text { duration (months) }\end{array}$ & & $12.63(7.07)$ & $.13-28$ & & 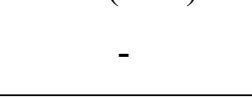 & \\
\hline Race/Ethnicity & $\%$ & & & $\%$ & & \\
\hline $\begin{array}{l}\text { African American/ } \\
\text { Black }\end{array}$ & $\begin{array}{c}0 \\
(N=0)\end{array}$ & & & $\begin{array}{c}6.90 \\
(N=4)\end{array}$ & & \\
\hline Asian- & 47.22 & & & 17.24 & & \\
\hline American/ Asian & $(N=17)$ & & & $(N=10)$ & & \\
\hline $\begin{array}{l}\text { European- } \\
\text { American/Caucasian }\end{array}$ & $\begin{array}{c}33.33 \\
(N=12)\end{array}$ & & & $\begin{array}{c}44.83 \\
(N=26)\end{array}$ & & \\
\hline Hispanic/Latino & $\begin{array}{c}5.56 \\
(N=2)\end{array}$ & & & $\begin{array}{c}6.90 \\
(N=4)\end{array}$ & & \\
\hline Other & $\begin{array}{l}13.89 \\
(N=5)\end{array}$ & & & $\begin{array}{c}1.72 \\
(N=1)\end{array}$ & & \\
\hline Mixed & $\begin{array}{c}0 \\
(N=0)\end{array}$ & & & $\begin{array}{c}17.24 \\
(N=10)\end{array}$ & & \\
\hline $\begin{array}{l}\text { Unknown/ } \\
\text { Not Specified }\end{array}$ & $\begin{array}{c}0 \\
(N=0)\end{array}$ & & & $\begin{array}{c}5.17 \\
(N=3)\end{array}$ & & \\
\hline Parental Education & $\%$ & & & $\%$ & & \\
\hline High school degree & $\begin{array}{c}0 \\
(N=0)\end{array}$ & & & $\begin{array}{c}1.72 \\
(N=1)\end{array}$ & & \\
\hline Some College & $\begin{array}{c}5.56 \\
(N=2)\end{array}$ & & & $\begin{array}{c}6.90 \\
(N=4)\end{array}$ & & \\
\hline $\begin{array}{l}\text { Community college/ } \\
\text { two-year degree }\end{array}$ & $\begin{array}{c}0 \\
(N=0)\end{array}$ & & & $\begin{array}{c}8.62 \\
(N=5)\end{array}$ & & \\
\hline $\begin{array}{l}\text { Four-year college } \\
\text { degree }\end{array}$ & $\begin{array}{l}22.22 \\
(N=8)\end{array}$ & & & $\begin{array}{l}15.52 \\
(N=9)\end{array}$ & & \\
\hline $\begin{array}{l}\text { Some graduate } \\
\text { school }\end{array}$ & $\begin{array}{l}16.67 \\
(N=6)\end{array}$ & & & $\begin{array}{c}8.62 \\
(N=5)\end{array}$ & & \\
\hline Master's degree & $\begin{array}{l}13.89 \\
(N=5)\end{array}$ & & & $\begin{array}{c}29.31 \\
(N=17)\end{array}$ & & \\
\hline Doctoral degree & $\begin{array}{l}16.67 \\
(N=6)\end{array}$ & & & $\begin{array}{c}17.24 \\
(N=10)\end{array}$ & & \\
\hline Professional degree & $\begin{array}{c}22.22 \\
(N=8)\end{array}$ & & & $\begin{array}{c}3.45 \\
(N=2)\end{array}$ & & \\
\hline $\begin{array}{l}\text { No parental education } \\
\text { listed }\end{array}$ & $\begin{array}{c}2.78 \\
(N=1)\end{array}$ & & & $\begin{array}{c}8.62 \\
(N=5)\end{array}$ & & \\
\hline
\end{tabular}


Note. $\mathrm{PI}=$ previously institutionalized $; \mathrm{F}=$ female; $M=$ mean; $S D=$ standard deviation; $\mathrm{CBCL}$ T-scores $=$ Child Behavior Checklist for Ages 6-18 Internalizing T-scores; Participants were free to report more than one race or ethnicity (Mixed) or to not report (Unknown/Not Specified); Parental education was obtained from the parent who provided consent for the study ( 80 female, 11 male, 3 not reported or not applicable); No parental education listed, parents who did not report their education level.

$* p<.05 .{ }^{* *} p<.01$ associated with independent samples t-tests. 